\title{
Patient and parent satisfaction with a dietitian- and nurse-led celiac disease clinic for children at the Stollery Children's Hospital, Edmonton, Alberta
}

\author{
Seema Rajani BSc ${ }^{1}$, Jessica Sawyer-Bennett BSc RD ${ }^{2,3}$, Leanne Shirton RN2,3, Gail DeHaan RN²,3, \\ Cheryl Kluthe RN BSCN ${ }^{2,3}$, Rabindranath Persad MBBS FRCPC ${ }^{3}$, \\ Hien Q Huynh MBBS FRACP FRCPC(Hon $)^{3}$, Justine Turner MBBS FRACP PhD ${ }^{2,3}$
}

\begin{abstract}
S Rajani, J Sawyer-Bennett, L Shirton, et al. Patient and parent satisfaction with a dietitian- and nurse-led celiac disease clinic for children at the Stollery Children's Hospital, Edmonton, Alberta. Can J Gastroenterol 2013;27(8):463-466.
\end{abstract}

OBJECTIVE: To assess patient and parent satisfaction with a primarily nurse- and dietitian-led celiac disease clinic in a tertiary pediatric centre.

METHODS: An online survey was sent to families and patients attending the Stollery Children's Hospital's Multidisciplinary Pediatric Celiac Clinic (Edmonton, Alberta) since 2007. The survey focused on clinic attendance, satisfaction with clinic structure, processes, and education and preference for alternatives to the current process. Respondents were asked to rank satisfaction or preference on a fivepoint Likert scale, with 1 being lowest and 5 being highest.

RESULTS: Most satisfaction related to follow-up with serology (4.6) and with a dietitian (4.3). The most preferred changes included either meeting the entire multidisciplinary team after the biopsy (4.7), or meeting with only the dietitian and nurse after the biopsy (4.4). The preferred education resources were the Internet (4.3) and the dietitian (4.2). The mean overall satisfaction score of the Multidisciplinary Pediatric Celiac Clinic was 4.0.

CONCLUSIONS: Results of the present survey suggested that patients and families value a multidisciplinary follow-up clinic for children with celiac disease. In particular, feedback based on repeat blood work and regular contact with a dietitian were highly valued. The present survey, outlining the most valued aspects of the clinic, may be useful for service delivery in other regions. In addition, it provides information on how to better support pediatric patients with celiac disease.

Key Words: Celiac disease/follow up; Dietitian/clinic; Pediatrics

\author{
La satisfaction des patients et des parents à l'égard \\ d'une clinique de maladie coliaque pour enfant \\ dirigée par une diététiste et une infirmière au Stollery \\ Children's Hospital d'Edmonton, en Alberta
} une clinique de maladie cœliaque surtout dirigée par une infirmière et une diététiste dans un centre pédiatrique de soins tertiaires.

MÉTHODOLOGIE : Les familles et les patients qui fréquentaient la clinique de maladie cœliaque pédiatrique multidisciplinaire du Stollery Children's Hospital d'Edmonton, en Alberta depuis 2007 ont reçu un sondage virtuel. Ce sondage portait sur la fréquentation de la clinique, la satisfaction envers la structure et les processus de la clinique, l'information et les préférences pour d'autres solutions que le processus courant. Les répondants ont été invités à classer leur satisfaction ou leur préférence sur une échelle de Likert en cinq points, un étant le plus bas et cinq, le plus haut.

RÉSULTATS : La plus grande satisfaction était liée au suivi de la sérologie $(4,6)$ et avec un diététiste $(4,3)$. Les changements préférés incluaient la rencontre avec toute l'équipe multidisciplinaire après la biopsie $(4,7)$ ou la rencontre avec le diététiste et l'infirmière après la biopsie $(4,4)$. Les ressources d'information favorisées étaient Internet $(4,3)$ et le diététiste $(4,2)$. L'indice de satisfaction global moyen de la clinique de maladie cœliaque pédiatrique multidisciplinaire s'élevait à 4,0.

CONCLUSION : Les résultats du présent sondage laissent supposer que les patients et les familles tiennent à l'existence d'une clinique de suivi multidisciplinaire pour les enfants ayant la maladie cœliaque. La rétroaction après les fréquents bilans sanguins et le contact régulier avec un diététiste, notamment, étaient très prisés. Le présent sondage, qui fait ressortir les aspects les plus appréciés de la clinique, peut être utile pour la prestation de services dans d'autres régions. En outre, il fournit de l'information sur la manière de mieux soutenir les patients d'âge pédiatrique ayant une maladie cœliaque.

lymphocytes (7). Damage to the mucosa in the biopsy is histologically graded using the Marsh criteria (9).

Presently, the only treatment for CD is a life-long gluten-free diet (GFD). Patients starting a GFD can show improvement in symptoms in several weeks and, with a strict adherence to the diet, this improvement can be tracked through blood work (10). Adherence to the diet can reduce the burden of disease, including reduction in mortality rate, risk of lymphoma and gastrointestinal cancers, to that of the general population $(6,8,11)$. The early implementation of a GFD in childhood can lead to a decreased risk of osteoporosis development in adulthood $(2,6,12)$. However, a GFD can be challenging and, in particular, patients are shown to be less compliant with the diet if they are asymptomatic at the time of diagnosis (4). Studies have shown that a supportive relationship and effective communication between a patient and their doctor or other health care workers can enhance dietary compliance $(11,13)$. Thus, the Stollery Children's Hospital (Edmonton, 


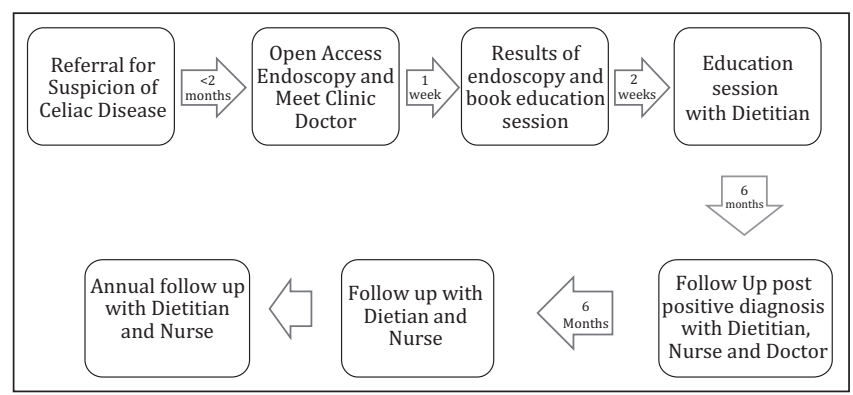

Figure 1) The patient process from time of referral through to annual followups in the Multidisciplinary Pediatric Celiac Clinic at the Stollery Children's Hospital, Edmonton, Alberta

Alberta) created the Multidisciplinary Pediatric Celiac Clinic, the first of its kind in Canada, for children diagnosed with CD in northern Alberta. The purpose of this clinic is to follow children from diagnosis with CD until 17 years of age, allowing annual access to a dietitian with substantial knowledge of CD. The structure of the clinic is unusual in that it is primarily led by a dietitian and a nurse, with limited contact with the doctor after the first six months. What is also unique to the Multidisciplinary Pediatric Celiac Clinic is that ongoing research is conducted within the context of the interdisciplinary team to evaluate current interventions related to treatment and program development. The purpose of annual visits to the clinic is to ensure the family has support, to provide continual education, and to check on the growth and well-being of the child. The hope is that this will promote adherence to the GFD. There is a general notion that an early diagnosis of $\mathrm{CD}$ - in addition to patient education, supervision and dietary counselling - will lead to better compliance (4).

The Multidisciplinary Pediatric Celiac Clinic team sent out a survey to examine the structure of clinic processes and overall patient satisfaction of the education provided by members of the interdisciplinary team. The survey was also a method to ensure that the clinic was fulfilling its role as a support for patients and families.

\section{METHODS}

Clinic structure and flow (Figure 1)

The Stollery Multidisciplinary Pediatric Celiac Clinic was established in 2007. The process for an individual patient begins with referral for suspicion of $\mathrm{CD}$, based on positive screening (aTTG and/or antiendomysial antibodies), or high index of clinical suspicion and/or subnormal immunoglobulin A level. Patients are referred directly to open-access endoscopy (OAE), provided they are on a gluten-containing diet. The average time from referral to endoscopy is $\leq 2$ months. On the day of the endoscopy, patients meet the Clinic doctor. The results of the endoscopy are available one week later and, at that time, the diagnosispositive $\mathrm{CD}$ patient is scheduled to meet with the dietitian to receive education. No more than a two-week lag period exists between biopsy results and the education appointment. At the end of the hour-long education session, written information is given to the family including: handouts on $\mathrm{CD}$ and the GFD; contact information for the clinic team; and Canadian Celiac Association (CCA) and tax benefits information. Six months after diagnosis, the patient is scheduled to meet the nurse, dietitian and doctor for further education. Before this appointment, they undergo blood work, consisting of repeat aTTG, complete blood count, vitamin D, iron and thyroid studies. The patient has an appointment at the Multidisciplinary Pediatric Celiac Clinic six months later and on an annual basis thereafter with the dietitian and nurse alone, with repeat blood work. The clinic doctor reviews all patient charts and blood results, including growth records, and is available for consultation, but has rarely been required. To ensure a follow-up appointment is scheduled, all referred and active patient data are entered into the clinic's database, which is maintained by the doctor and nurses.

\section{Satisfaction survey}

The Multidisciplinary Pediatric Celiac Clinic team developed an online survey; the web address was mailed to all families and patients in the database since 2007. Ethics approval for the survey was granted by the University of Alberta Research Ethics Board (Edmonton, Alberta). The anonymous online survey was created and managed by the Women and Children's Health Research Informatics Core, using REDCap (14) (Research Electronic Data Capture) electronic data capture tools.

The survey asked four generic questions: who completed the survey; the patient's age at diagnosis; and two questions regarding the frequency of the family's attendance at clinic. Eleven questions regarding specific aspects of the clinic and their satisfaction were asked including: the nurse, dietitian, doctor, the same-day endoscopy, blood tests, and growth recording and the clinic overall. They were asked eight questions that rated alternative approaches to the current clinic structure. These included: a clinic visit before biopsy; having a doctor/ nurse/dietitian/community doctor alone follow the patient; group teaching session for patients and families; and meeting other families that have a child diagnosed with CD. Finally, 11 questions asked participants to rate their satisfaction, since diagnosis, with the information provided by the the Multidisciplinary Pediatric Celiac Clinic; specific clinic members; community doctors; the Internet; books; and the CCA.

\section{RESULTS}

\section{Survey completion and clinic attendance}

A total of 225 surveys were mailed and a total of 61 surveys were completed: $75 \%$ were completed by a mother, $12 \%$ by a father and $3 \%$ by the patient (10\% were not specified). The majority $(98 \%)$ of the patients were diagnosed when they were $>1$ year of age and had been attending the clinic yearly since diagnosis (77\%). Only 3\% had attended the clinic only once, $10 \%$ came only a few times and then stopped, and 3\% reported they had no knowledge of the clinic. Of the families that never attended or stopped visiting the clinic, reasons included: inconvenience (five of 23); the family believed they knew all they needed to follow a GFD (four of 23); the clinic was not helpful (three of 23); they wanted to see a doctor (three of 23); and they were not given an appointment (eight of 23).

\section{Clinic satisfaction}

Participants in the survey were asked to rank how useful supports provided by the Multidisciplinary Pediatric Celiac Clinic were on a scale of 1 to 5 , with 1 being the least useful and 5 being the most useful. In order, the top five rankings (mean score) were: blood work (4.6); meeting with the dietitian (4.3); the written information given (4.1); having the child weighed and measured (3.9); and having telephone access to the nurse (3.7). The three lowest ranked were: meeting the nurse (3.6); coming to the hospital (3.5); and not meeting the doctor (2.2). The general overall satisfaction with the participants' experience at the Clinic was rated on a scale of 1 to 5 , with 1 being least useful and 5 being most useful; the overall ranking was 4.0 .

\section{Alternative approaches to clinic processes}

Participants in the survey were asked to rank how useful the following changes to the Clinic would be for their child and family on a scale of 1 to 5 , with 1 being the least useful and 5 being the most useful. The top five (mean score) changes included: meeting the dietitian, nurse and doctor in clinic post biopsy (4.7); meeting with the dietitian and nurse only postbiopsy (4.4); meeting with their pediatrician or family doctor postbiopsy (3.7); teaching sessions with other families (3.7); and teaching sessions for teenagers with other teens (3.7). The three lowest ranked changes were meeting with other families that had a child diagnosed with CD (3.6), meeting with the celiac clinic doctor only postbiopsy (3.2) and having a clinic visit before biopsy (3.0). 


\section{Information resources for $\mathrm{CD}$ families}

Participants in the survey were asked to rank resources providing information to the patient and family about CD and a GFD on a scale of 1 to 5 , with 1 being the least useful and 5 being the most useful. The top rankings for sources of information were: the Internet (4.3), the dietitian (4.2), the CCA (4.1), books (4.1) and the Multidisciplinary Pediatric Celiac Clinic (3.9). The three that ranked least useful were other parents (3.2), the community pediatrician (2.9) and the family doctor (2.8). The majority of respondents reported that all of the information they required was provided after the first teaching session $(67 \%)$, while $33 \%$ believed they needed more information than was provided at that one session.

\section{Comments}

In the final part of the survey, participants were asked to provide suggestions on how to improve the service provided by the Multidisciplinary Pediatric Celiac Clinic. Common themes were: having blood test results available to discuss at the time of appointment; having more peer support for families: "A group situation would be great especially in the beginning as it would help the child to know she is not the only one"; and staggering all the information delivered at the education session over a number of sessions: "There is just so much to learn at first. It wouldn't have mattered who did the session or what they said. People need time to process. An idea have the first teaching session and a follow-up in say in six weeks to see how it is going and to give families time to try and come back with questions". In addition, some families expressed surprise at the supports available to them that they were not aware of such as telephone access to the nurse or dietitian.

\section{DISCUSSION}

Treatment for CD requires a lifelong commitment to a GFD. The smallest ingestion of gluten can trigger an immune reaction (15). Similar to any disorder that requires a substantial change in lifestyle, patients and the families of pediatric patients need support and encouragement $(2,4)$. Studies have shown that earlier implementation of a GFD will lead to better compliance for CD patients $(6,11,16)$. We believe it is essential for patients to obtain the support and information they need at an early age. The Multidisciplinary Pediatric Celiac Clinic at the Stollery Children's Hospital provides patients and families with ongoing support by professionals who are knowledgeable in managing $\mathrm{CD}$ and committed to improving life-long health outcomes for these children.

The results of the present study suggest that most families (77\%) continue to regularly attend the Multidisciplinary Pediatric Celiac Clinic after diagnosis. In addition, measures of satisfaction were generally very positive. This clinic is unique in that it is led by a dietitian and nurse to provide education and support. This reduces the resources required to have a physician versed in $\mathrm{CD}$ regularly follow these patients. By using our resources wisely, we can provide regular followup until children transition to young adulthood. Only $17 \%$ of families stopped attending the clinic because they had all of the information they believe they needed. It was more common to stop attending due to the inconvenience of coming to the hospital for an appointment (21\%). This is not surprising because the clinic services a wide geographical area for northern Alberta. In fact, we would argue the high attendance suggest that the annual clinic reviews are valued by families of children with CD. A strong theme in the positive feedback given by families was the value they placed on the report of their child's compliance with the GFD, based on blood work and growth recording.

Resources provided by the Multidisciplinary Pediatric Celiac Clinic found to be most useful for patients and families were regular meetings with the dietitian and the written information given to them during their education session. The involvement of a dietitian in the education and support of patients and families on management of CD and a GFD has shown to lead to a better adherence to GFD (11). A GFD can be demanding and expensive; the dietitian can ensure that patients achieve their nutritional goals and give them the knowledge to add variety to their meals. Along with their knowledge of nutrition, dietitians are practiced in motivational interviewing, providing the encouragement needed for a patient to make a lifestyle change (17). The educational package given to the patients and families in our clinic includes a general guide to $\mathrm{CD}$ and nutritional handouts (18-20) regarding a GFD. From the comments received, the educational session was noted to be quite overwhelming and ideas for more sessions in a shorter span of time were suggested. Giving written material with the same information as one would receive in the educational seminar postbiopsy for review before the seminar could be helpful in giving patients and families time to process the information as well as helping those families who find it inconvenient to drive to the clinic.

Although some research suggests controversy regarding the process of an OAE (21), the present survey did not suggest that families found the $\mathrm{OAE}$ to be a major concern. In fact, respondents indicated that visiting the clinic before the biopsy would be the least useful change compared with other possible changes in the process. In contrast, respondents believed it would be useful to have a postbiopsy clinic visit with a nurse, dietitian and doctor altogether (this does not occur until six months on the GFD in the current structure). Interestingly, despite this, the doctor ranked seventh in the top 10 sources of information. Therefore, we believe it remains valid to have the nurse and dietitian continue to provide the first teaching session postbiopsy, to reduce physician time and provide timely education.

The present survey also showed that participants found the community pediatrician and family doctor to be least effective in providing the patient and their family with information about CD and a GFD. They were ranked ninth and 10th, respectively, of the other 10 information resources. Given the increasing prevalence of $\mathrm{CD}(2)$, this is a disappointing finding. There is onus on community general pediatricians and family doctors to know more about this common disease, as well as for academic centres, such as our own, to provide them teaching and training. With better education on the diagnosis, management and treatment of $\mathrm{CD}$, frontline physicians could provide an essential and convenient support for patients unable to access a specialist clinic, and to assume the role of being ongoing primary caregivers with regard to $\mathrm{CD}$.

Effective knowledge is key to improving health outcomes in chronic diseases - CD is no exception $(4,11)$. Knowledge of how to manage a lifelong diet, where to obtain the foods in a cost-effective manner and how to reduce the risk of cross contamination are essential to maintain the patient's health. In the present survey, it was clear the most effective sources of information for the patient and their family were the dietitian, the Internet and books. The CCA was also shown to be a valuable source of information for families. Studies have shown that parents being part of a local celiac chapter leads to an increase in compliance in their children $(6,8,11)$. The CCA has many programs, one of which an 'anti-panic session' was highly recommended among respondents. We currently actively encourage families to join the CCA and use their website resources.

The present survey identified some issues regarding miscommunication to be addressed by the team. In particular, some families were unaware they could seek advice from the nurse and/or dietitian between clinic visits. Although we currently distribute contact information at the education session, this may not be absorbed at the time and, in the future, we will address this with written information given to the patients and families at that time. In addition, some strategies to link families together and provide peer support, such as evening presentations/get-togethers, will be explored by the team. Providing families and children with $\mathrm{CD}$ an opportunity to interact may be helpful to reduce isolation and knowledge sharing, including knowledge exchange: recipes, restaurants and other local resources. Based on the survey feedback the current clinic structure does not, on its own, appear to foster this exchange.

One limitation of the present survey was the modest response rate (27\%), which was below the $30 \%$ to $50 \%$ that might be expected from 
an online or mailed survey. In addition, our respondents would have been to the Multidisciplinary Pediatric Celiac Clinic for a varied number of visits that was not ascertained. Time from diagnosis would certainly be one factor that may influence the perceived value of the clinic or their concerns over alternative processes and sources of information. It would have been useful to clarify the exact time for which families had been attending clinic.

$\mathrm{CD}$ is becoming increasingly prevalent due, in part, to greater awareness and screening of at-risk populations (2). Given both the increase in diagnosis and our recognition of significant long-term health impact, there is a need to provide more support for children and families on how to manage this disorder. Lack of adherence to the GFD has shown that this treatment is clearly a challenge for sufferers and requires significant adjustment for them and their families. Studies have shown that consistent follow-up, support and encouragement

\section{REFERENCES}

1. Ryan M, Grossman S. Celiac disease: Implications for patient management. Gastroenterol Nurs 2011;34:225-8.

2. Evans KE, Hadjivasilou M, Sanders DS. Understanding 'silent' coeliac disease: Complications in diagnosis and treatment. Gastrointest Nurs 2010;8:26,28-32.

3. Fasano A, Catassi C. Current approaches to diagnosis and treatment of celiac disease: An evolving spectrum. Gastroenterology 2001;120:636-51.

4. Högberg L, Grodzinsky E, Stenhammar L. Better dietary compliance in patients with coeliac disease diagnosed in early childhood. Scand J Gastroenterol 2003;38:751-4.

5. Elfström P, Granath F, Ye W, Ludvigsson J. Low risk of gastrointestinal cancer among patients with celiac disease, inflammation, or latent celiac disease. Clin Gastroenterol Hepatol 2012;10:30-6.

6. Rostom A, Murray JA, Kagnoff MF; AGA Institute: American Gastroenterological Association (AGA) Institute technical review on the diagnosis and management of celiac disease. Gastroenterology 2006;131:1981-2002.

7. Hopper AD, Cross SS, Hurlstone DP, et al. Pre-endoscopy serological testing for coeliac disease: Evaluation of a clinical decision tool. BMJ 2007;334:729.

8. Holmes S. Coeliac disease: Symptoms, complications and patient support. Nurs Stand 2010;24:50-6.

9. Marsh MN. The natural history of gluten sensitivity: Defining, refining and re-defining. QJM 1995;88:9-13.

10. Nachman F, Sugai E, Vázquez H, et al. Serological tests for celiac disease as indicators of long-term compliance with the gluten-free diet. Eur J Gastroenterol Hepatol 2011;23:473-80.

11. Martin S. Against the grain: An overview of celiac disease. J Am Acad Nurse Pract 2008;20:243-50. from dietitians and doctors are necessary for the well-being of patients with CD $(8,17)$. We believe that our clinic represents a novel and effective means to provide this support. The present survey suggests that attending families value the Multidisciplinary Pediatric Celiac Clinic at the Stollery Children's Hospital. It highlights the most valued aspects of the current clinic structure and has shed light on future options that would better support families and pediatric patients with CD. Currently, we are conducting research in our clinic on long-term dietary compliance and dietary quality of children with CD compared with children with CD at other centres and health community controls. We hope to show that regular follow-up in a multidisciplinary clinic will improve dietary adherence and outcomes. On that basis, we suggest that the novel use of a dietitianand nurse-led team will enable this model to be cost-effectively replicated in many other centres.

12. Norström F, Lindholm L, Sandström O, Nordyke K, Ivarsson A. Delay to celiac disease diagnosis and its implications for healthrelated quality of life. BMC Gastroenterol 2011;11:118.

13. Ukkola A, Mäki M, Kurppa K, et al. Patients' experiences and perceptions of living with coeliac disease - implications for optimizing care. J Gastrointestin Liver Dis 2012;21:17-22.

14. Harris PA, Taylor R, Thielke R, Payne J, Gonzalez N, Conde J. Research electronic data capture (REDCap) - A meta data-driven methodology and workflow process for providing translational research informatics support. J Biomed Inform 2009;42:377-81.

15. Laurin P, Wolving M, Falth-Magnusson K. Even small amounts of gluten cause relapse in children with celiac disease. J Pediatr Gastroenterol Nutr 2002;34:26-30.

16. Wagner G, Berger G, Sinnreich U, et al. Quality of life in adolescents with treated coeliac disease: Influence of compliance and age at diagnosis. J Pediatr Gastroenterol Nutr 2008;47:555-61.

17. Stuckey C, Howdle P, Lowdon J. Symposium 1: Joint BAPEN and British Society of Gastroenterology symposium on 'coeliac disease: Basics and controversies' dietitians are better than clinicians in following up coeliac disease [electronic resource]. Proc Nutr Soc 2009;68:249-51.

18. Canadian Celiac Association. <www.celiac.ca/> (Accessed December 2012).

19. Gluten-Free Diet A Comprehensive Resource Guide. Gluten Free Diet. <http://glutenfreediet.ca/> (Accessed December 2012).

20. National Institute of Diabetes and Digestive and Kidney Diseases (NIDDK). Celiac Disease Awareness Campaign. <www.celiac.nih. gov/Default.aspx > (Accessed December 2012)

21. Eisen GM, Baron TH, Dominitz JA, et al. Guidelines: Open access endoscopy. Gastrointest Endosc 2002;56:793-5. 


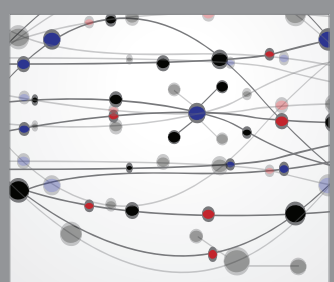

The Scientific World Journal
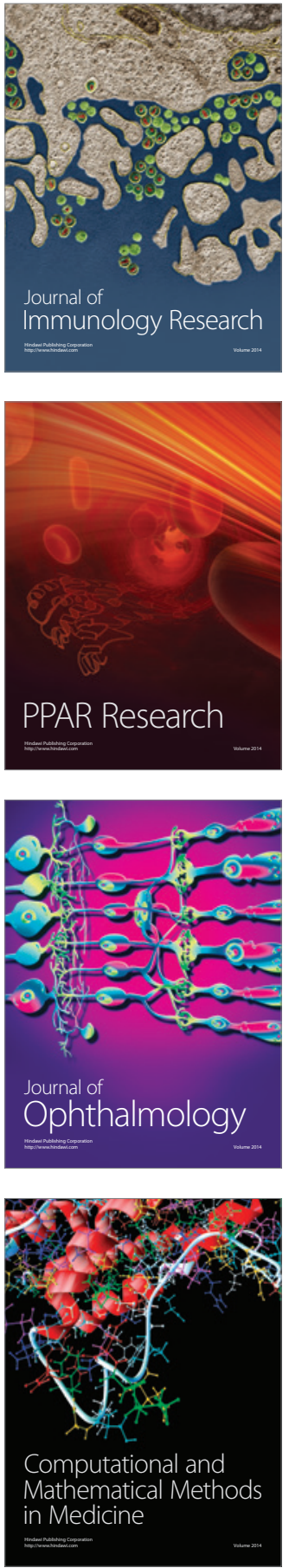

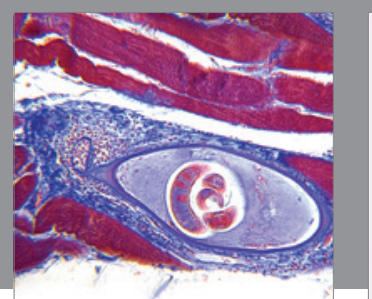

Gastroenterology Research and Practice

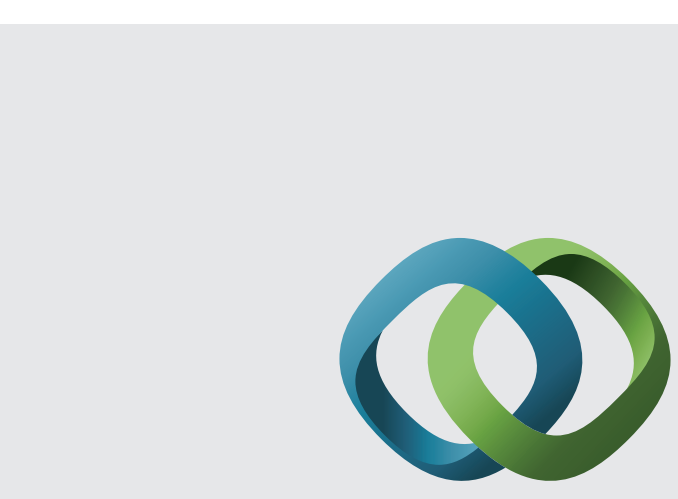

\section{Hindawi}

Submit your manuscripts at

http://www.hindawi.com
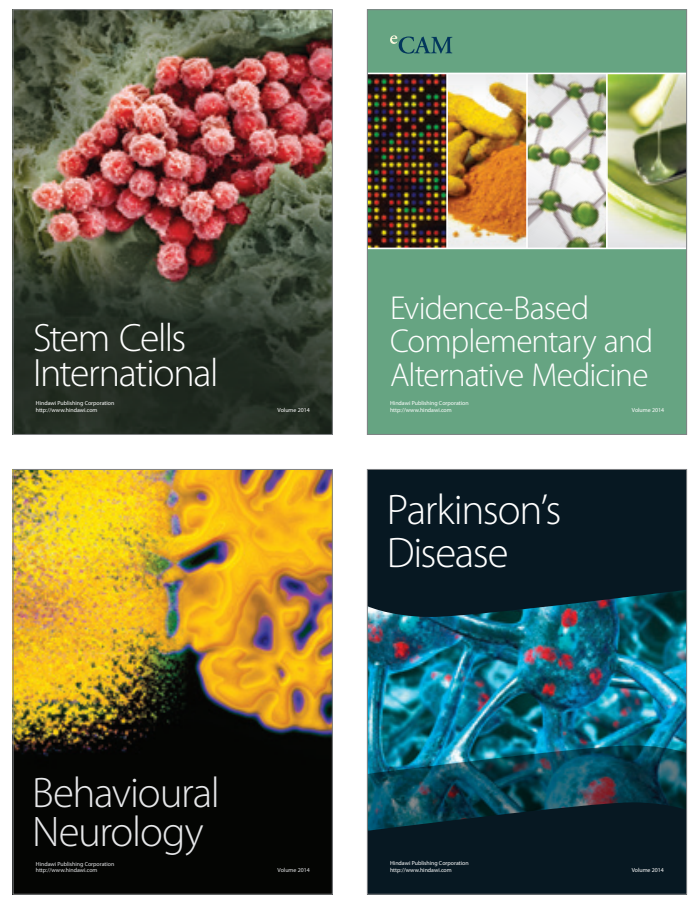
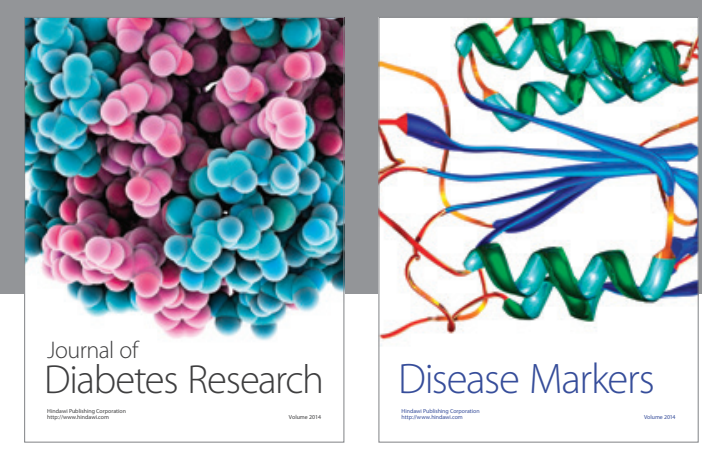

Disease Markers
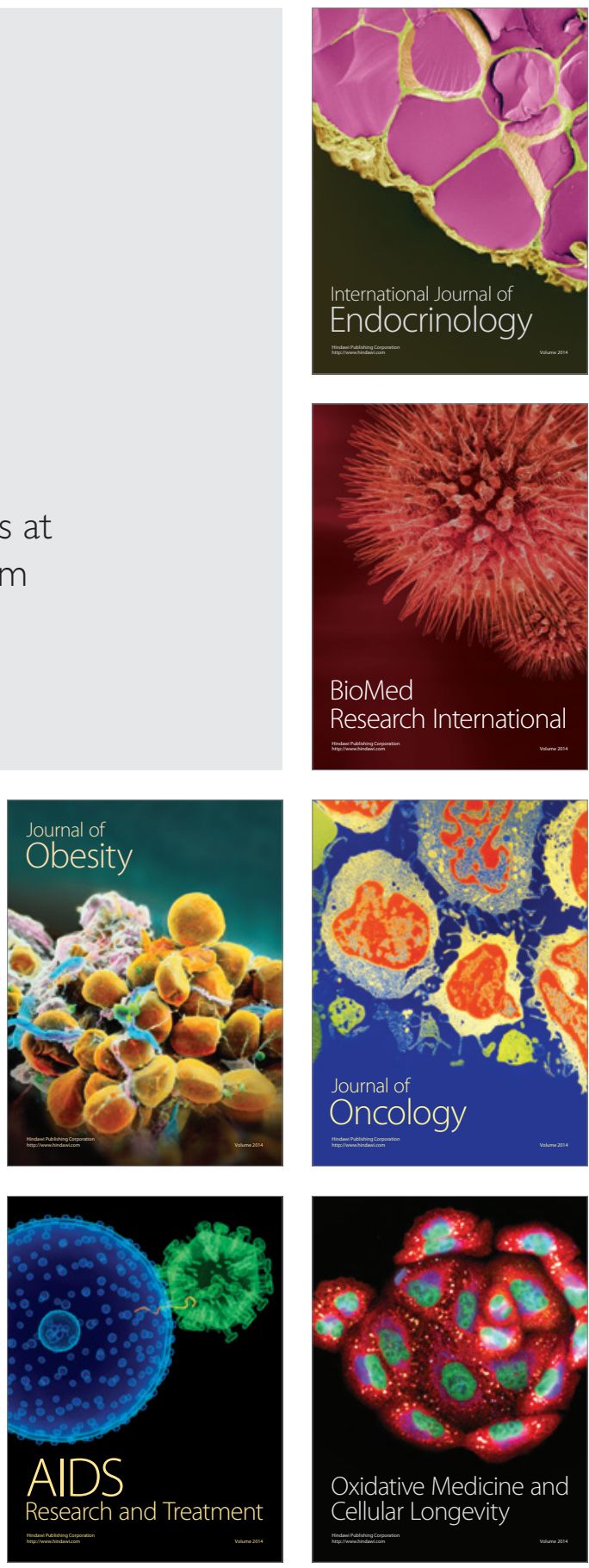